\title{
ANALYSIS OF SIMULATED RADAR ALTIMETRIC WAVE FORMS FOR POLAR ICE AND SNOW SURFACES
}

\section{(Abstract)}

by

Eva Novotny*

(Scott Polar Research Institute, University of Cambridge, Cambridge CB2 IER, U.K.)

\section{ABSTRACT}

The radar altimeter of the satellite Seasat has proved that ice and snow surfaces in the polar regions can return meaningful signals if the terrain is not excessively rugged or sloping. Because the use of the leading edge of the wave forms for height determination entails inherent uncertainties and, at best, provides only a single datum per wave form, the entire wave forms should be studied. Excesses or deficiencies in amplitude at various ranges within a single wave form, and the changes that occur in successive wave forms, can be analysed to yield information on the geometric and scattering properties of features observed by the altimeter.

Results from computer simulations are presented, showing how (1) a margin of sea ice (sinusoidal in the model) can be mapped, (2) the boundaries of two isolated ice floes can be outlined, (3) sea-ice concentrations can be derived within annuli about the nadir of an individual footprint, and (4) for land ice, the elevations of topographic features, together with the general slope of the ground, can be determined if an imaging instrument that operates simultaneously with the altimeter provides the outlines of these features. In examples (1) and (2), it is assumed that the ice is contiguous wherever that is possible, to permit the analytical reconstruction of the ice margin or individual ice floes in the presence of the inevitable ambiguity in the position of any feature with respect to the two sides of the satellite track. Example (4) requires that the altimeter record correctly records the strongest signals returned by ice-packs. This condition is not fulfilled by any existing radar altimeter, but it may be achieved in the next generation of these instruments. In additional examples of information from entire wave forms, the effects of crevasses and sastrugi in reducing or re-distributing the energy of the returned signals are also illustrated.

Full details of these analyses and results will be published at a later date.

\section{ICEBERGS IN THE SOUTHERN OCEAN}

\section{(Abstract)}

\author{
by
}

Olav Orheim

(Norsk Polarinstitutt, P.O. Box 158, 1330 Oslo Lufthavn, Norway)

ABSTRACT

Relatively little data on the distribution of Antarctic icebergs were available prior to 1980. The published literature included size data of about 5000 icebergs, and position data of 12000 icebergs. There were indications that the size data were biased in favour of larger icebergs.

A programme of systematic iceberg observations was therefore initiated by Norsk Polarinstitutt in 1981 through the SCAR Working Group on Glaciology. This programme is based on standard "blue" forms distributed to all ships going to Antarctica. The icebergs are recorded every $6 \mathrm{~h}$ and in five length groups: $10-50,50-200,200-500$, and $500-1000 \mathrm{~m}$, and those over $1000 \mathrm{~m}$ are described individually.

The amount of data has increased greatly from the start in 1981-82. The position of 70000 icebergs, including 50000 that had been size classified, were on file at Norsk Polarinstitutt by December 1985, and the data set is growing rapidly. Most ships travelling to and from Antarctica now participate in collection of the data. (Fig.1 shows the locations of the icebergs sighted.)

The size distribution of the classified icebergs observed under this programme up to December 1985 is given in Table I:

* Present address: Department of Applied Mathematics and Theoretical Physics, Silver Street, Cambridge, U.K.
TABLE I.

\begin{tabular}{|c|c|c|c|c|c|c|}
\hline \multirow{2}{*}{$\begin{array}{l}\text { Size } \\
\text { class } \\
\mathrm{m}\end{array}$} & \multirow[t]{2}{*}{$\begin{array}{c}\text { Total } \\
\text { number }\end{array}$} & \multicolumn{3}{|c|}{ "Standard size" } & \multicolumn{2}{|c|}{$\begin{array}{c}\text { Total } \\
\text { volume }\end{array}$} \\
\hline & & $\%$ & & $\mathrm{~m}$ & $10^{9} \mathrm{~m}^{3}$ & $\%$ \\
\hline $10-50$ & 17788 & 34.9 & 30 & $\times 25 \times 20$ & 0.3 & $<0.1$ \\
\hline $50-200$ & 17187 & 33.7 & $120 \times$ & $\times 100 \times 80$ & 17 & 1 \\
\hline $200-500$ & 10437 & 20.5 & $320 \times$ & $\times 280 \times 200$ & 187 & 8 \\
\hline $500-1000$ & 4152 & 8.2 & 750 & $\times 600 \times 250$ & 467 & 20 \\
\hline$>1000$ & 1400 & 2.7 & meas & s. individ. & 1379 & 70 \\
\hline & 50954 & 100.0 & & & 2050 & 100. \\
\hline
\end{tabular}

The "standard size" (length, width, and thickness) is based on our observations from three Antarctic expeditions which carried out dedicated iceberg studies. Many icebergs are of course not right-angled parallelepipedal in shape, but this is a good approximation for most of the larger icebergs.

The data are based both on visual sightings and on radar observations. Duplicate observations from a ship moving at slow or zero speed are as far as possible eliminated, both during observation, and by critical appraisal before the data are filed. The data editing also includes evaluation of data quality, especially in connection with radar observations, and comparison of positions and dimensions of the large icebergs in order to reduce to a minimum repeated observations from different vessels of 